
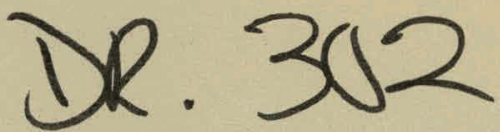

OMNDIA REPORT SAND81-0115A • Unlimited Release • UC-71 Printed January 1982
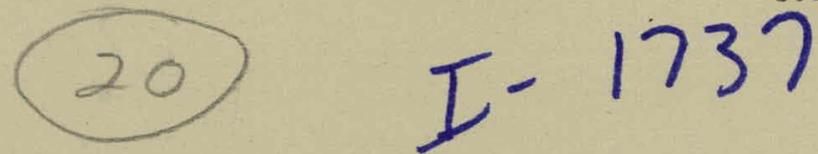

\title{
Analysis of a System for the Measurement of Impact Loads
}

\author{
Mathias J. Sagartz
}

\section{Prepared by}

Sandia National Laboratories

Albuquerque, New Mexico 87185 and Livermore, California 94550

for the United States Department of Energy

under Contract DE-AC04-76DP00789

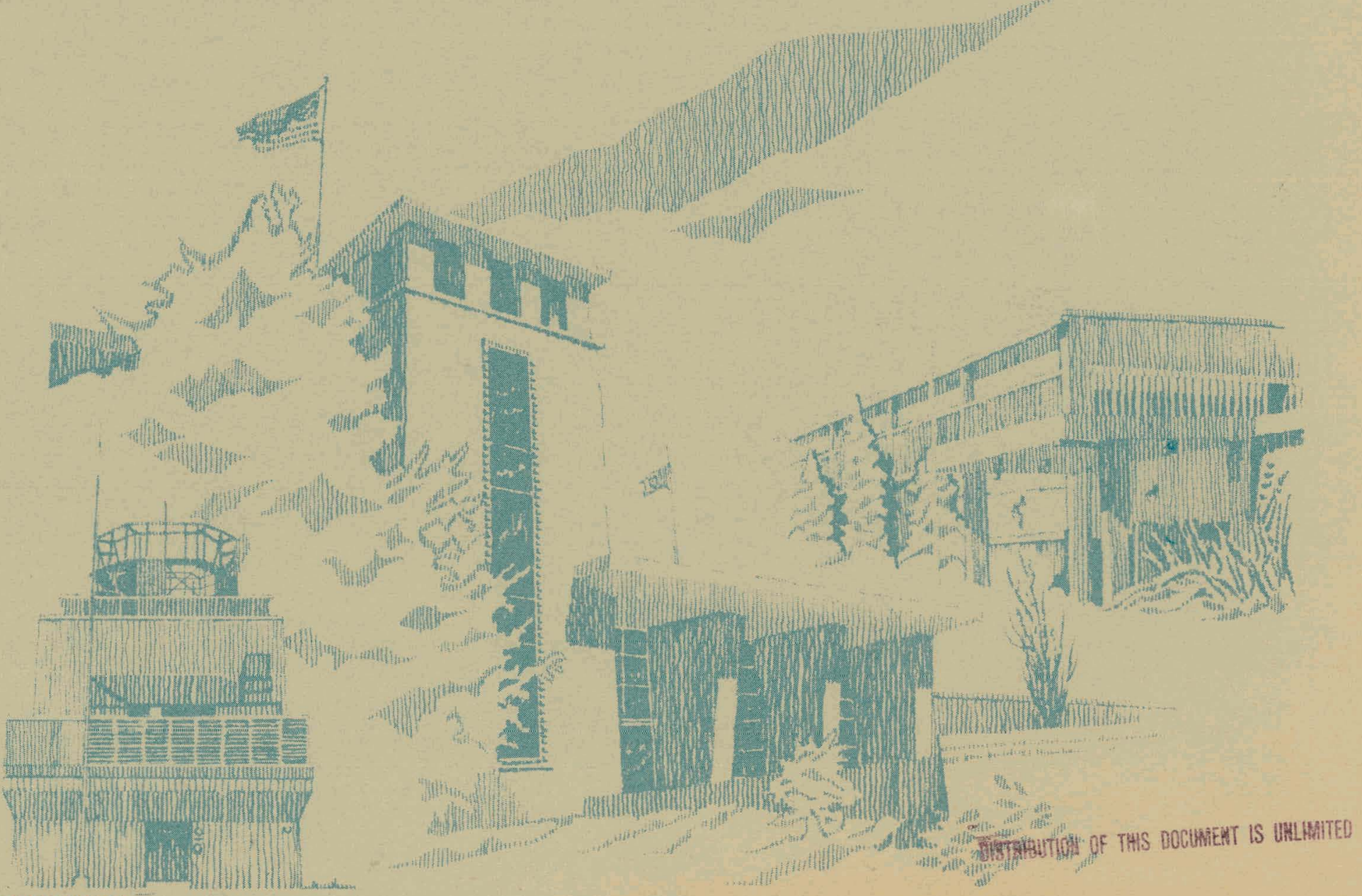




\section{DISCLAIMER}

This report was prepared as an account of work sponsored by an agency of the United States Government. Neither the United States Government nor any agency Thereof, nor any of their employees, makes any warranty, express or implied, or assumes any legal liability or responsibility for the accuracy, completeness, or usefulness of any information, apparatus, product, or process disclosed, or represents that its use would not infringe privately owned rights. Reference herein to any specific commercial product, process, or service by trade name, trademark, manufacturer, or otherwise does not necessarily constitute or imply its endorsement, recommendation, or favoring by the United States Government or any agency thereof. The views and opinions of authors expressed herein do not necessarily state or reflect those of the United States Government or any agency thereof. 


\section{DISCLAIMER}

Portions of this document may be illegible in electronic image products. Images are produced from the best available original document. 
Issued by Sandia National Laboratories, operated for the United States Department of Energy by Sandia Corporation.

NOTICE: This report was prepared as an account of work sponsored by an agency of the United States Government. Neither the United States Government nor any agency thereof, nor any of their employees, nor any of their ment nor any agency thereof, nor any of their employees, nor any of their or implied, or assumes any legal liability or responsibility for the accuracy, completeness, or usefulness of any information, apparatus, product, or process disclosed, or represents that its use would not infringe privately owned rights. Reference herein to any specific commercial product, process, or service by trade name, trademark, manufacturer, or otherwise, does not tracter by the United States Govly its end by the United States Government, any agency thereof or any of their contractors or subcontractors. The views and opinions expressed herein do not necessarily state or reflect those of the United States Government, any agency thereof or any of their contractors or subcontractors.

\section{Printed in the United States of America} Available from

National Technical Information Service

U.S. Department of Commerce

5285 Port Royal Road

Springfield, VA 22161

NTIS price codes

Printed copy: A03

Microfiche copy: A01 


\section{PAGES 1 to 2 WERE INTENTIONALLY LEFT BLANK}


SAND81-0115A

TIC -0186

$U C-71$
SAND $-81-0115 \mathrm{~A}$

DE82 011695

\title{
Analysis of a System for the Measurement of Impact Loads*
}

Mathias J. Sagartz

Division 5523

Sandia National Laboratories

Edited by

Robert M. Jefferson, Manager

Nuclear Materials Transportation Technology Department

\author{
Prepared For
}

TRANSPORTATION TECHNOLOGY CENTER

Sandia National Laboratories

Albuquerque, NM 87185

\section{ABSTRACT}

A reinforced flat plate supported on load cell force transducers is proposed as a system for measuring the dynamic force of an impact test. The system is mathematically modeled as a beam on elastic supports loaded at its midspan by a half sine pulse. Analytical expressions are derived for the force vs time in the load cells and are shown to be functions of three parameters, the ratio of the load duration to the fundamental frequency of the system, the ratio of support stiffness to beam flexural stiffness and the ratio of the distance between supports to the total beam span. The results of calculations made for a range of parameters are presented and discussed. It is shown that the load cells should not be located at the end of the beam. Optimum results are obtained by placing them directly under what would be the nodal points of the fundamental beam vibration mode if the beam were in a free-free condition. As an example, a hypothetical impact test including estimates for peak force and duration is considered and a drop table suitable for the test is designed.

*This work was performed at Sandia National Laboratories and was supported by the U.S. Department of Energy under contract number DE-ACO4-76DP00789. 


\section{TABLE OF CONTENTS}

$\underline{\text { Page }}$

Abstract. . . . . . . . . . . . . . . . 3

Introduction. . . . . . . . . . . . . . 5

Preliminary Consideration . . . . . . . . . . . . 5

Analysis.................... . . 7

Parameter Study. . . . . . . . . . . . . . . 13

Numericd Example..................... 16

Conclusions..................... . . . 17

References. . . . . . . . . . . . . . . . 18

Table 1..................... . . 1y

Figures 1-6................... . . . . . . . . . . . . 


\section{INTRODUCTION}

Containers used to ship nuclear materials must be tested under impact conditions to insure that they meet crash-worthiness standards set by the Nuclear Regulatory Commission. Testing can be anything from the simple pass-fail type with only a framing camera recording the event to a specimen with dozens of accelerometers and strain gauges. How best to instrument a test specimen is not an easy question because the very severe impact environment causes a complex structural response. This complexity also makes the interpretation of test data a formidable task. One useful piece of data that may be obtainable is the overall force-time history of the impact. This data would provide a good check on any structural model that is being used to predict container response. A system being considered for making this measurement consists of a very stiff impact plate supported by high rigidity load cells. This report presents an analysis done in support of organization 4552 's efforts to develop such a system.

\section{Preliminary Considerations}

The drop table system is simply an elastic structure that is subject to short duration load pulses. Initial sizing of the system requires knowledge of or estimates for the specimen size, peak impact force, load duration and how accurately the location of the impact will be controlled. The plate must be sufficiently rigid so that the impact load on the specimen is essentially the same as it would be for an impact onto a rigid surface. The lateral plate dimensions and the spacing between the supporting load cells is determined by the size of the specimen and the accuracy of impact loeation.

For purposes of analysis, the system is considered as an unsupported beam or plate loaded by the impact and also by the supports (load cells). Figure 1 is a sketch of such a system. If the applied load were static, equilibrium would require that 
the sum of the reactions from the load cells equal the applied load. In the case of a dynamic load, the system vibrates and the reaction at the load cells oscillates relative to the applied load; Figure 2. The problem in designing a drop table load measuring system is to minimize the difference between the applied load and the reaction in the load cells, i.e., the "error". shown in Figure 2. A significant cause of this difference is the dynamic amplification of the structural response modes excited by the loads.

Basic vibration theory shows that dynamic amplification is minimized by making the periods of the modes excited by a load pulse as small as possible relative to the load duration'. In this case the load pulse is applied to the center of the structure and the only way to maximize the frequencies of the response modes is to stiffen the structure. The excitation due to the support loads also drives the structure and at first it would seem that little can be done here to maximize the frequencies of the modes participating in the response other than to make the load cells very stiff. However, this is not the case. By positioning the load cells at the node points of the fundamental mode of the dron tahle, the reactions do not. excite the lowest frequency mode and only the higher frequency modes arc driven. Also, by ulacing the load cells at the nodal points, the fundamental mode, to whatever extent it is excited by the impact load, will not contribute to the response at the supports. In this way the mode with the highest dynamic amplification factor is eliminated from the output.

Some important assumptions are implicit in the above reasoning. First, the load pulse is assumed to be unronupled from the drop table rigidity. That is, the drop table is very rigid compared to the crash specimen so that small changes in the drop table stiffness will not cause any change in the fore vs time of the impact force. Also the load cell transducer used as a support is assumed to have a frequency response capability adequate to monitor the system's structural modes. 
Finally, the rigidity of the load cell supports is assumed to be high enough so that the fundamental mode for the system is the same as the first mode of the drop table without supports. clearly this is not the case if the load cell rigidity becomes very smal1. In that case the fundamental mode is the impact table behaving as a rigid mass supported on springs, and there are no nodal points at which to place the supports.

The forced vibration of a plate supported at discrete points is not simple to analyze. The basic ideas and physics are the same as for beam oscillations but finding the mode shapes and corresponding frequencies is very complex. The analysis done here will consider only a beam model of the drop table. This model is much more amenable to analys is and can be used to develop an understanding of the basic phenomena occurring under impact conditions. As will be shown in a numerical example, a drop table system can be designed in such a way that it can properly be modeled as a beam and the analysis is directly applicable. If the drop table is a plate, the analysis may still be useful in a qualitative sense, but specific numerical calculations needed for an actual design should be done with a plate model.

\section{Analys is}

A beam of length $2 L$, flexural rigidity EI and mass per unit length $\rho A$ is supported by symmetrically located springs with spring constant $k$ spaced a distance $2 l$ apart. The sysleill is initially at rest and at time $t=0$ is loaded at its center, $x=0$. The load is modeled as a point load in space and a half-sine pulse in time, Psin $\Omega t$ for $0<t<\frac{\pi}{\Omega}$ and 0 for all other times. The purpose of analyzing this structure is to determine how closely the reaction load, $V$, in the support springs (i.e. load cells) follows the applied load. That is, under what conditions can the output of the load cells provide an accurate measure of the impact pulse. 
A static analysis of a simply supported beam loaded by a concentrated force, $P$, at the center shows that a modal solution for this problem does not give a quickly convergent solution for the reaction force. Writing the beam solution as a sum of trigonometric functions gives this representation for the force at each support,

$$
V=\frac{2 P}{\pi} \sum_{n=1}^{\infty} \frac{(-1)^{\frac{n-1}{2}}}{n} \quad n \text { odd on } 1 y .
$$

A similar slowly convergent. series can be expected for the dynamic problem of interest here if a straightforward modal solution is used. This inconvenience can be avoided by using a slightly modified form of solution commonly known as william's method. 2 The solution for the beam displacement, $w$, is written as two parts; $w_{S}$, a quasi-static solution, and $w_{D}$, a dynamic part. In terms of this decomposition of the displacement, the governing equation is

$$
E I\left(w_{S}^{I V}+w_{D}^{I V}\right)+\rho A\left(\ddot{w}_{S}+\ddot{w}_{D}\right)=P \delta(x) \sin \Omega t H\left(\frac{\pi}{\Omega}-t\right)
$$

where now ws satisfies

$$
\operatorname{EI} w_{S}^{I V}=P \delta(x) \sin \Omega t H\left(\frac{\pi}{\Omega}-t\right)
$$

In this report the symbols $\left(^{\prime}\right),()^{\prime}$ and ()$^{\text {IV }}$ represent $\frac{\partial}{\partial t}(), \frac{\partial()}{\partial x}$ and $\frac{\partial^{4}}{\partial x^{4}}()$, respectively, and $H$ is the Heaviside step function, i.e., $H(Z)=1$ if $Z>0$ and $=0$ if $Z<0$. Substituting (2) into (1) gives an equation for the dynamic part of the solution

$$
E I w_{D}^{I V}+\rho A \ddot{w}_{D}=-\rho A \frac{\partial^{2} w_{s}}{\partial t^{2}}
$$

For this problem 


$$
\begin{aligned}
w_{s} & =\left\{\frac{P}{2 k}-\frac{P \ell^{3}}{2 E I}\left[\frac{1}{3}-\frac{1}{2} \frac{x^{2}}{\ell^{2}}+\frac{1}{6} \frac{x^{3}}{\ell^{3}}\right]\right\} \sin \Omega t H\left(\frac{\pi}{\Omega}-t\right) & \\
& =\left[\frac{P}{2 k}+\frac{P \ell^{3}}{4 E I}\left(1-\frac{x}{\ell}\right)\right] \sin \Omega t H\left(\frac{\pi}{\Omega} t\right) & 0<x<\ell
\end{aligned}
$$

The initial conditions are that the table is initially at rest

$$
\begin{aligned}
& w(x, 0)=w_{S}(x, 0)+w_{D}(x, 0)=0 \\
& w(x, 0)=w_{S}(x, 0)+w_{D}(x, 0)=0
\end{aligned}
$$

and the boundary conditions are

$$
\begin{aligned}
& w(0, t)=w^{\prime}(0, t)=0 \text { or } \\
& w_{D}(0, t)=w_{D}(0, t)=0 \\
& w^{\prime \prime}(L, t)=w^{\prime} \cdot(L, t)=0 \text { or } \\
& w^{\prime \prime}(L, t)=w^{\prime}{ }^{\prime}{ }_{D}(L, t)=0
\end{aligned}
$$

Also matching conditions are required for continuity at the location of the spring supports. Since the static solution was constructed to satisfy these conditions, the dynamic solution must satisfy them on its own just as in the boundary conditions 


$$
\begin{aligned}
& w_{D}\left(l^{-}, t\right)=w_{D}\left(l^{+}, t\right) \\
& w_{D}^{\prime}\left(l^{-}, t\right)=w_{D}^{\prime}\left(l^{+}, t\right) \\
& w_{D}^{\prime \prime}\left(l^{-}, t\right)=w_{D}^{\prime \prime}\left(l^{+}, t\right) \\
& k w_{D}(l, t)=-E I\left[w_{D}^{\prime \prime \prime}\left(l^{-}, t\right)-w_{D}^{\prime \prime \prime}\left(l^{+}, t\right)\right]
\end{aligned}
$$

Here $\ell^{+}$and $\ell^{-}$indicate points just to the right and left respectively of $x=\ell$. The solution for $w_{D}$ is found using a slandard modal-type approach. That is $w_{D}$ is represented in the torm of a series

$$
w_{D}=\dot{\Sigma} a_{n}(t) \phi_{n}(x)
$$

where the $\phi_{n}$ are mode shapes for the $n^{\text {th }}$ eigenvalue, $\lambda_{n}$, i.e. $\phi_{n}(x)$ satisfies

$$
E I \phi_{n}^{I V}+\left(\frac{{ }_{n}}{l}\right)^{4} \rho A \phi_{n}=0
$$

and the matching and boundary conditions (7) and (8) with $\phi_{n}$ substituted for $w_{0}$. Substituting the form of the solution (9) into the guverning equation (3) gives

$$
E I \frac{\partial^{4}}{\partial x^{4}} \sum a_{n}(t) \phi_{n}(x)+\rho A \cdot \frac{\partial^{2}}{\partial t^{2}} \sum a_{n} \psi_{n}(x)=-\rho A \frac{\partial^{2} w_{s}}{\partial t^{2}}
$$

If equation (10) is multiplied hy $f_{m}$ and all terils in (10) are integrated over $0<x<L$, the orthogonality of the mode shapes uncouples the resulting equations to one equation for each unknown $a_{n}$

$$
\text { i.e. } \ddot{a}_{n}(t)+\left(\frac{\ell}{\lambda_{n}}\right)^{4} \frac{\rho A}{E I} a_{n}(t)=\frac{-\int_{0}^{L} \frac{\partial^{2} w_{s}}{\partial t^{2} \phi_{n}}(x) d x}{\int_{0}^{L} \phi_{n}^{2} d x}
$$

For convenience a dimensionless time is introduced 


$$
\tau=\frac{t}{\ell^{2}} \sqrt{\frac{E I}{\rho A}}
$$

and Equation (11) becomes

$$
\frac{d^{2} a_{n}}{d \tau^{2}}+\frac{1}{\lambda_{n}^{2}} a_{n}=-b_{n} \sin \omega \tau H\left(\frac{\pi}{\omega}-\tau\right)
$$

where

$$
b_{n}=\int_{0}^{L} w_{s}\left(x, \frac{\pi}{2 \omega}\right) \phi_{n}(x) d x / \int_{0}^{L} \phi_{n}^{2} d x
$$

and

$$
\omega=\Omega \cdot l^{2}(\rho A / E I)^{\frac{1}{-s}}
$$

It is a relatively simple but tedious matter to find the eigenvalues and mode shapes and to prove orthogonality of the eigenfunctions, therefore these details are not included here. with the eigenvalues, modes shapes and $w_{s}$ known, all terms in Equation (13) are defined and the solution is written

$$
a_{n}(\tau)=A \sin \lambda_{n}^{2} \tau+B \cos \lambda_{n}^{2} \tau+\int_{0}^{\tau} \frac{\sin \lambda_{n}^{2}(\tau-t)}{\lambda_{n}^{2}}\left(-b_{n}(t)\right) d t
$$

To obtain initial conditions that must be satisfied by the $a_{n}$ 's, the series expression for $w_{0}$,. Equation (9), is substiuted into Equation (6), the terms are multiplied by $\phi_{n}(x)$ and the result is integrated over $0<x<L$. The result is

$$
\begin{aligned}
a_{n}(0) & =-\int_{0}^{L} w_{s}(x, 0) \phi_{n} d x / \int_{0}^{L} \phi_{n}^{2} d x=0 \\
\frac{d a_{n}}{d t}(0) & =-\int_{0}^{L} \frac{d w_{s}}{d \cdot}(x, 0) \phi_{n} d x / \int_{0}^{L} \phi_{n}^{2} d x \\
& =b_{n} \omega
\end{aligned}
$$


The solution satisfying these initial conditions is

$a_{n}(\tau)=b_{n}\left\{\frac{\omega}{\lambda_{n}^{2}} \sin \lambda_{n}^{2} \tau+\int_{0}^{\tau} \cdot \frac{\sin \lambda_{n}^{2}(\tau-t)}{\lambda_{n}^{2}} \frac{d^{2}}{d t^{2}}\left[\sin \omega t H\left(\frac{\pi}{\omega}-t\right)\right] d t\right\}$

and using integration by parts on the convolution integral in (18) gives

$$
\left.\left.a_{n}(\tau)=b_{n} \mid-\sin \omega \tau H\left(\frac{\pi}{\omega}\right)-\tau\right)+\lambda_{n}^{2} \int_{0}^{\tau} \sin \lambda_{n}^{2}(\tau-t) \sin \omega t H\left(\frac{\pi}{(1)}-t\right) d t\right\}
$$

With this expression for the Fourier coefficients the reaction force in the load cell can be written

$$
\begin{aligned}
v & =k w(l, \tau)=k\left\{w_{s}(l, \tau)+\sum_{n=1}^{\infty} a_{n}(\tau) \phi_{n}(l)\right\} \\
& =\frac{p}{2} \sin \omega \tau H\left(\frac{\pi}{\omega}-\tau\right)+k \sum_{n=1}^{\omega} a_{n}(\tau) \phi_{n}(l)
\end{aligned}
$$

The terms in the bottom line of Equation (20) can be interpreted as the ideal behavior of the support (exactly tracking the applied load) and a series representation of an error tërm, i.e. at any instant. the difference between the force at one support and half the applied load.

The mode shapes are symmetrical about $x=0$ and are given by

$\phi_{n}(x)= \begin{cases}\cos \lambda_{n} \frac{x}{\ell}+c_{1 n} \cosh \lambda_{n} \frac{x}{\ell} & 0<x<\ell \\ c_{2 n}\left(\sin \lambda_{n} \frac{x}{\ell}+\sinh \lambda_{n} \frac{x}{\ell}\right)+c_{3 n}\left(\cos \lambda_{n} \frac{x}{\ell}+\cosh \lambda_{n} \frac{x}{l}\right) \ell<x<L\end{cases}$ 
where $C_{1 n}, C_{2 n}$, and $C_{3 n}$ are constants determined by requiring $\Phi_{n}$ to satisfy Equations (7) and (8). The convolution integral in (19) can be written in closed form as

$$
\begin{aligned}
& \int_{0}^{\tau} \sin \lambda_{n}^{2}(\tau-t) \sin \omega t H\left(\frac{\pi}{\omega}-t\right) d t= \\
& \sin \lambda_{n}^{2} \tau\left[\frac{\cos \left(\lambda_{n}^{2}-\omega\right) \tau-1}{2\left(\lambda_{n}^{2}-\omega\right)}-\frac{\sin \left(\lambda_{n}^{2}+\omega\right)}{2\left(\lambda_{n}^{2}+\omega\right)}\right] \\
& -\cos \lambda_{n}^{2} \tau\left[\frac{\sin \left(\lambda_{n}^{2}-\omega\right) t}{2\left(\lambda_{n}^{2}-\omega\right)}-\frac{\sin \left(\lambda_{n}^{2}+\omega\right) \tau}{2\left(\lambda_{n}^{2}+\omega\right)}\right] 0<\tau<\frac{\pi}{\omega}
\end{aligned}
$$

and

$$
\frac{\omega}{\omega^{2}-\lambda_{n}^{4}}\left[\sin \lambda_{n}^{2} \tau+\sin \lambda_{n}^{2}\left(\tau-\frac{\pi}{\omega}\right)\right] \quad \tau>\frac{\pi}{\omega}
$$

The solution for the support force depends on three physical parameters; the support span to beam length ratio, $\frac{\ell}{L}$; the load cell rigidity vs beam rigidity, $\frac{\mathrm{kl} \ell^{3}}{\mathrm{EI}}$; and the ratio of load duration to half the period of the fundamental mode, $\frac{\pi}{\omega}$. When values for these parameters are given, a simple numerical algorithm can be used to find the eigenvalues, compute $\phi_{n}(l)$ and $b_{n}$, and calculate results at a series of times $\tau$. In general unless $\frac{\pi}{\omega}$ is much less than one, the modal series in Equation (20) converges very quickly with only 3 or 4 modes required for an accurate solution. A simple computer program was written to perform these calculations and produce plots of the error vs time.

\section{Parameter Study}

A numerical study was performed to quantify the difference between the applied load and the force measured by the load cells, i.e. the "error", for a reasonable range of parameters. 
The general trends shown by the results are as expected; i.e. stiffer load cells (large $\frac{\mathrm{Kl}^{3}}{\mathrm{EI}}$ ) and longer duration loads ( $\frac{\pi}{\omega}$ large) reduce the measurement error. Also the idea of locating the load cells at the node points of the fundamental free-free beam mode is shown to be very effective. Table 1 presents a comparison of the errors for beams with no overhang vs beams with enough overhang so that the supports are at the first mode nodal points. A couple of examples may help the reader to interpret the physical meaning of the parameters in Table 1 . When $k l^{3} / E I$ is 3 the beam deflection for a static load is half due to beam flexure and half due to compression of the elastic support. Larger values of this parameter indicate increased stiffness of the load cell relative to the beam. When $\omega$ is $\frac{\pi}{2}$, the load duration is $1 / 2$ of the fundamental period of a beam with no overhang and rigid supports. Smaller values of $w$ correspond to longer load duration relative to the fundamental beam period.

The results in Table 1 show that when $w$ is less than .4 and $\mathrm{k} \ell^{3} / E \mathrm{I}$ is large, i.e., on the order of 100 , the maximum "error" can be kept less than 10\%, and in this regime having an overhang halves the peak error. As the support rigidity decreases, the efficacy of the overhang is somewhat diminished, but it is always better to have the overhang. Small variations in the amount of overhang were considered and in all cases the nodal point support location, $\ell / L=.55$, was indeed the optimum. Figures 3 and 4 show examples of the error vs time. for different sets of parameters. Because the series in Equation (2) is very rapidly convergent, the error plots are Uumlnated by the lowest contributing mode and approximate simple sinusoids. Finally, Figure 5 is a plot of peak error as a function of the support stiffness parameter $k \ell^{3} / E I$ for two different load durations. Note that the effect of changing the supiort stiffness is magnified by relatively shorter duration load pulses. 


\section{Numerical Example}

As an example an impact test of a quarter scale model of a proposed spent fuel shipping cask design is considered. A rough estimate for the impact load gives a peak force of $600,000 \mathrm{~N}(135,000$ 1b) with a load duration of about .05 sec. The specimen size is such that a span between load cells of $1.22 \mathrm{~m}(4 \mathrm{ft})$ should be adequate. A trial drop table design consists of two $W 10 \times 49$ structural steel beams with their top flanges welded to a $2.54 \mathrm{~cm}$ ( 1 in) thick steel plate of dimensions $.76 \mathrm{~m} \times 2.7 \mathrm{~m}(3 \mathrm{ft} \times 7 \mathrm{ft} 3 \mathrm{in})$. The beams are aligned with the longer plate dimension and four load cells, two for each beam, are used to support the assembly. A sketch of the table is shown in Figure 6 .

The first step in analysing this drop table is to locate the neutral axis and then calculate the moment of inertia about this axis. By definition the first moment of the cross section about the neutral axis is zero. If "e" is the distance from the centroid of the beam to the neutral axis (see figure 6), the value of e must satisfy

$$
-A_{1} e+a h\left(\frac{d}{2}+\frac{h}{2}-e\right)=0
$$

and

$$
e=\frac{a h\left(\frac{d}{2}+\frac{h}{2}\right)}{a h+A_{1}}
$$

where $A_{1}$ is the cross sectional area of the beam. The moment of inertia of the composite section about the neutral axis, I, is then calculated by using the parallel axis theorem

$$
\begin{aligned}
I / 2= & I_{1}+A_{1} e^{2}+a h^{3} / 12+a h\left(\frac{d}{2}+\frac{h}{2}-e\right)^{2} \\
& =I_{1}+a h^{3} / 12+A_{1} e\left(\frac{d}{2}+\frac{h}{2}\right)
\end{aligned}
$$


where $I_{1}$ is the tabulated moment of inertia for the beam. The maximum stress in the section occurs at the fibers farthest from the neutral axis

$$
\sigma_{\text {MAX }}=\frac{M\left(\frac{d}{2}+e\right)}{I}
$$

where $M$ is the maximum absolute value of the bending moment. Unless the impact load is unexpectedly severe or the drop table design is faulty, the dynamic amplification of the bending moment will be small and the peak bending moment should approach the static value $P \ell / 2$ ( $P$ is the peak force).

For the particular design given above, $e=78 \mathrm{~mm}(3.06 \mathrm{\prime \prime})$, $I=.430 \times 10^{-3} \mathrm{~m}^{4}\left(1034 \mathrm{in}^{4}\right)$ and $w=.047$. Calculations for the maximum measurement error in the load cells were made assuming two different load cell stiffnesses, .56 $\times 10^{9} \mathrm{~N} / \mathrm{m}$ $\left(3.2 \times 10^{6} \mathrm{lb} / \mathrm{in} ; \mathrm{k} \ell^{3} / \mathrm{EI}=2.95\right)$ and $5.6 \times 10^{9} \mathrm{~N} / \mathrm{m}$ $\left(32 \times 10^{6} \mathrm{lb} / \mathrm{in} ; \mathrm{k} \ell^{3} / \mathrm{EI}=29.5\right)$. The lower stiffness case corresponds to an actual measurement of the rigidity of a 100 ton hydraulic jack modified to act as a force transducer. The peak measurement errors for these load cell stiffnesses were calculated to be $3.9 \%$ and $1.8 \%$. nynamis amplification of the bending moment is less than $3 \%$ for both rases so the peak bending stress in the table is approximately

$$
\sigma_{\text {MAX }}=\frac{P \ell\left(e+\frac{d}{2}\right)}{2 I}=87 \mathrm{MPa}(12,600 \mathrm{psi})
$$




\section{Conclusions}

The results of this study show that a load measuring drop table system is feasible provided the rigidity of both the supports and the table itself can be made sufficiently high so that the system's natural frequencies are high enough to keep $\omega<.4$. Of course for a real system the impact surface may be a plate and repeating the analysis done here for this type of system is not feasible in closed form. Nevertheless, the ideas presented here should carry through and the support load cells should be placed on the nodal line of the fundamental plate mode. There is every reason to expect that the plate analysis will show results analogous to the beam. analysis. A system of the type described here cannot be expected to give detailed information about the load history. Small irregularities and local plateaus on the load curve are very high frequency phenomenona that the system simply cannot follow. However, for a reasonably smooth curve such as would be expected in cases of large plastic deformation, the system should perform quite well. 
1. Thompson, W. T., "Theory of Vibration with Applications," Prentice-Hall Inc., Englewood Cliffs, NJ, 1972, p. 94, Figure $4.5-3$.

2. Williams, D., "Displacements of a linear elastic system under a given transient load," Aeronautical Quarterly, Vol 1. $123-136(1949)$ 
TABLE $\quad$

MAX. ERROR/PEAK LOAD INTENSITY

$\frac{2 \mathrm{~V}-\mathrm{P} \sin \omega \tau}{\mathrm{P}}$

$0<\tau<\frac{\pi}{\omega}$

\begin{tabular}{l|c|c|c|c|c|c} 
& \multicolumn{2}{|c}{} & $\frac{\mathrm{K} \ell^{3}}{\mathrm{EI}}=1000$ & \multicolumn{2}{|c}{$\frac{\mathrm{K} \ell^{3}}{\mathrm{EI}}=48$} & \multicolumn{2}{c}{$\frac{\mathrm{k} \ell^{3}}{\mathrm{EI}}=6$} \\
$\omega$ & $\ell / \mathrm{L}=\mathrm{I}$ & $\ell / \mathrm{L}=.552$ & $\ell / \mathrm{L}=\mathrm{I}$ & $\ell / \mathrm{L}=.552$ & $\ell / \mathrm{L}=1$ & $\ell / \mathrm{L}=.552$ \\
\hline$\frac{\pi}{2}$ & 1.61 & .53 & 1.72 & .88 & 2.0 & 1.66 \\
1.4 & 1.41 & .45 & 1.50 & .74 & 1.84 & 1.60 \\
1.2 & 1.14 & .36 & 1.23 & .59 & 1.58 & 1.37 \\
1.0 & .87 & .29 & .94 & .46 & 1.28 & 1.10 \\
.8 & .62 & .23 & .66 & .34 & .95 & .82 \\
.6 & .41 & .16 & .43 & .25 & .63 & .54 \\
.5 & .32 & .13 & .34 & .20 & .48 & .41 \\
.4 & .25 & .11 & .26 & .16 & .35 & .30 \\
.3 & .18 & .081 & .19 & .11 & .25 & .21 \\
.2 & .12 & .054 & .12 & .074 & .16 & .13 \\
.1 & .055 & .027 & .056 & .036 & .073 & .062 \\
.05 & .027 & .013 & .029 & .018 & .036 & .030
\end{tabular}


Distribution:

U. S. Department of Energy, Superintendent of Documents

DOE/TIC - 4500 - R67 UC - 71 (166)

Washington, D.C. 20545

Attn:

G. Oertel

D. J. McGoff

F. P. Falci

R. F. Garrison

T. A. Anderson

U. S. Department of Energy

A ibuquerque Operations office

Albuquerque, NM 87115

Attn: $\quad$ K. Carlson, Transportation Program Manager

R. Y. Lowrey, Chief, Waste Management Branch

U. S. Nuclear Regulatory Commission

Mail Stop NL5650

Washington, D. C. 20555

Attn: J.C. Malaro

1535

2325

3141

3151

4000

4500

4550

D. C. Bickel

K. G. Mcliaghey

T. L. Werner (5)

W. L. Garner (3)

A. Narath

E. H. Beckner

Attn: W. D. Weart

R. W. Lynch

M. L. Kramm

4551

R. M. Jefferson

4551

R. E. Luna

4552

4552

4552

4553

4553

4700

5500

5510

5520

5522

5522

5523

5530

8266

TTC Library (3) FILE REF NO. 3003.024

W. B. Leisher

R. B. Pope

M. G. Vigil

G. C. Allen

H. R. Yoshimura

J. H. scott

0. E. Jones

D. B. Hayes

T. B. Lane

R. A. May

M. J. Sagarle (7)

R. C. Reuter, Jr.

W. Herrmann

E. A. Aas

For DOE/TIC (Unlimited Release) 


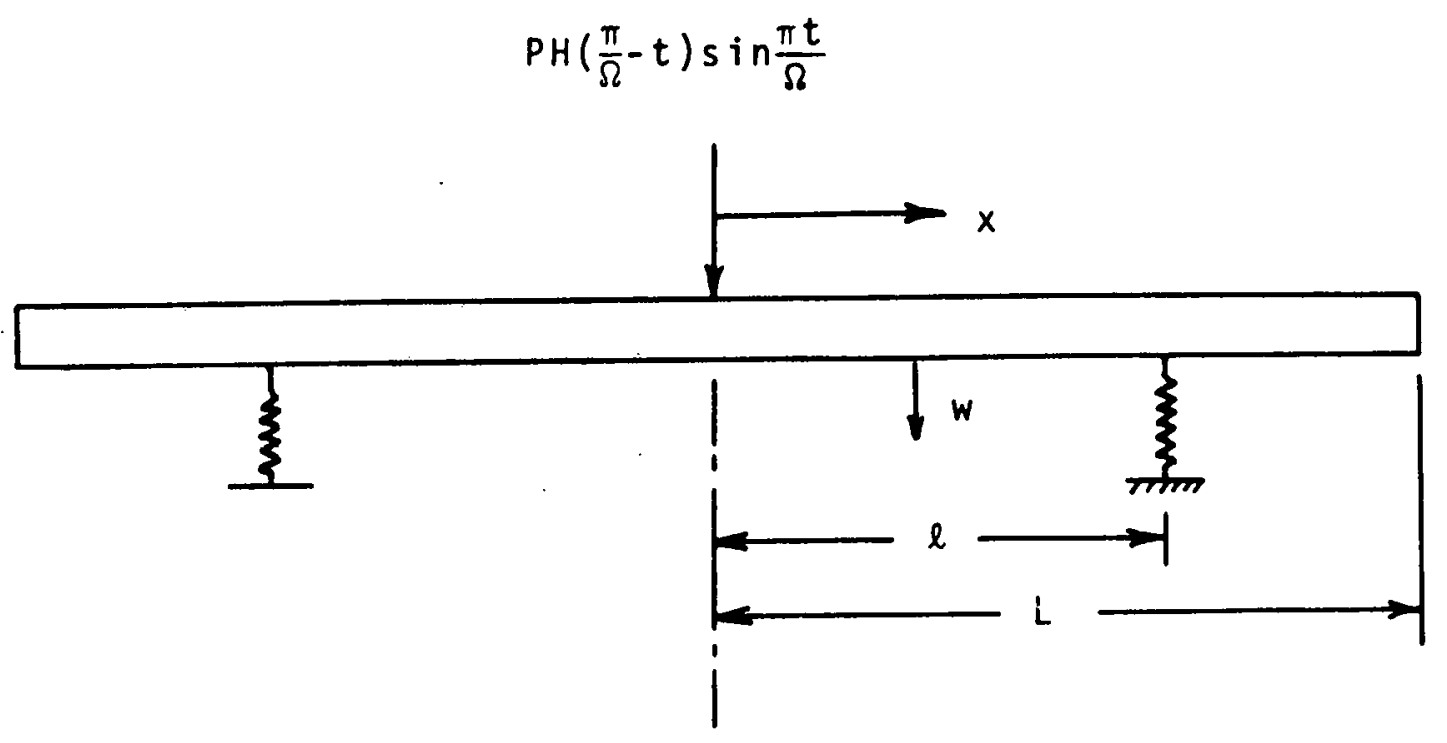

figure 1. Sketch of Mathematical Model

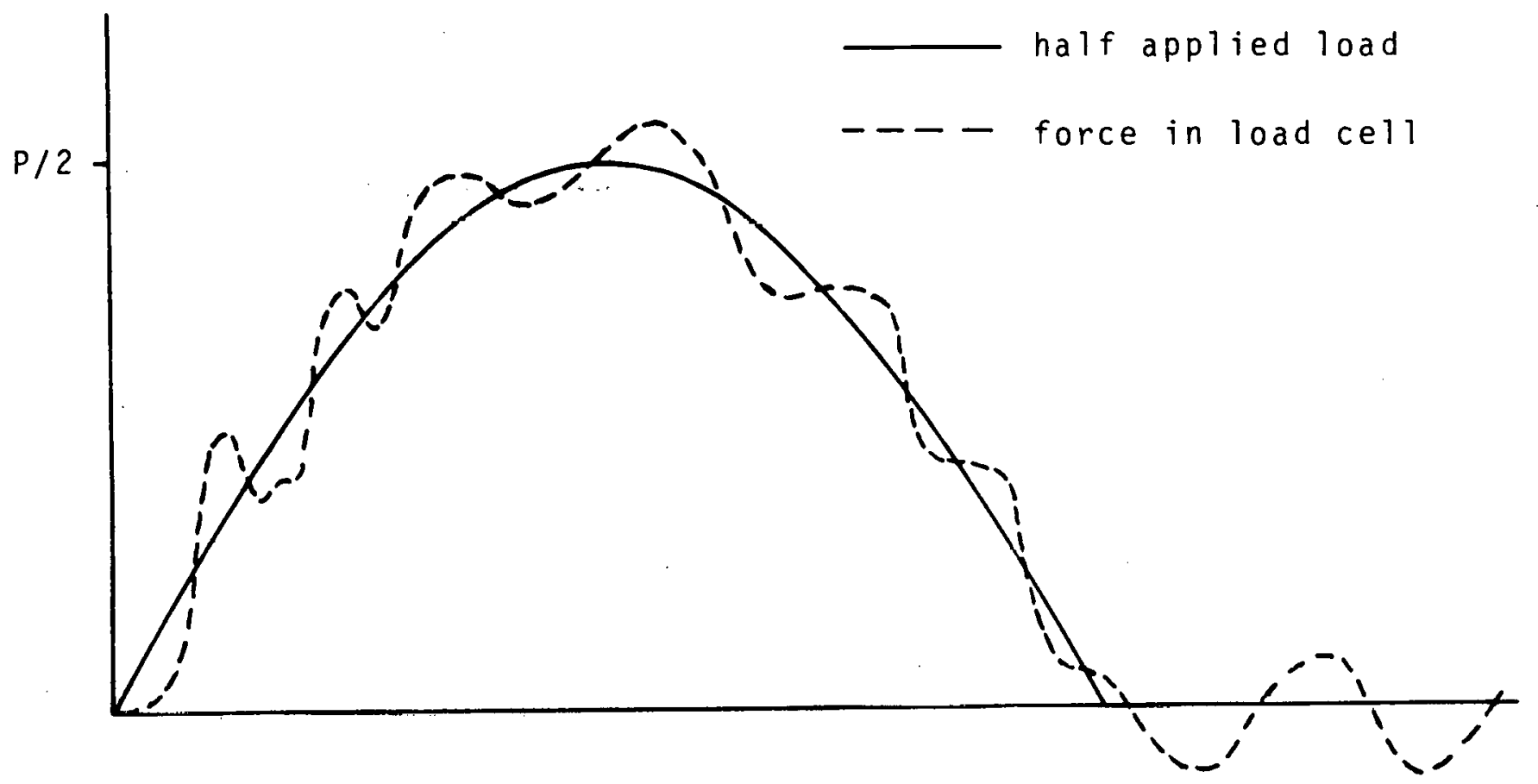

Figure 2. Sketch of a Comparison Between the Force in One Load Cell and Half of the Applied load. 


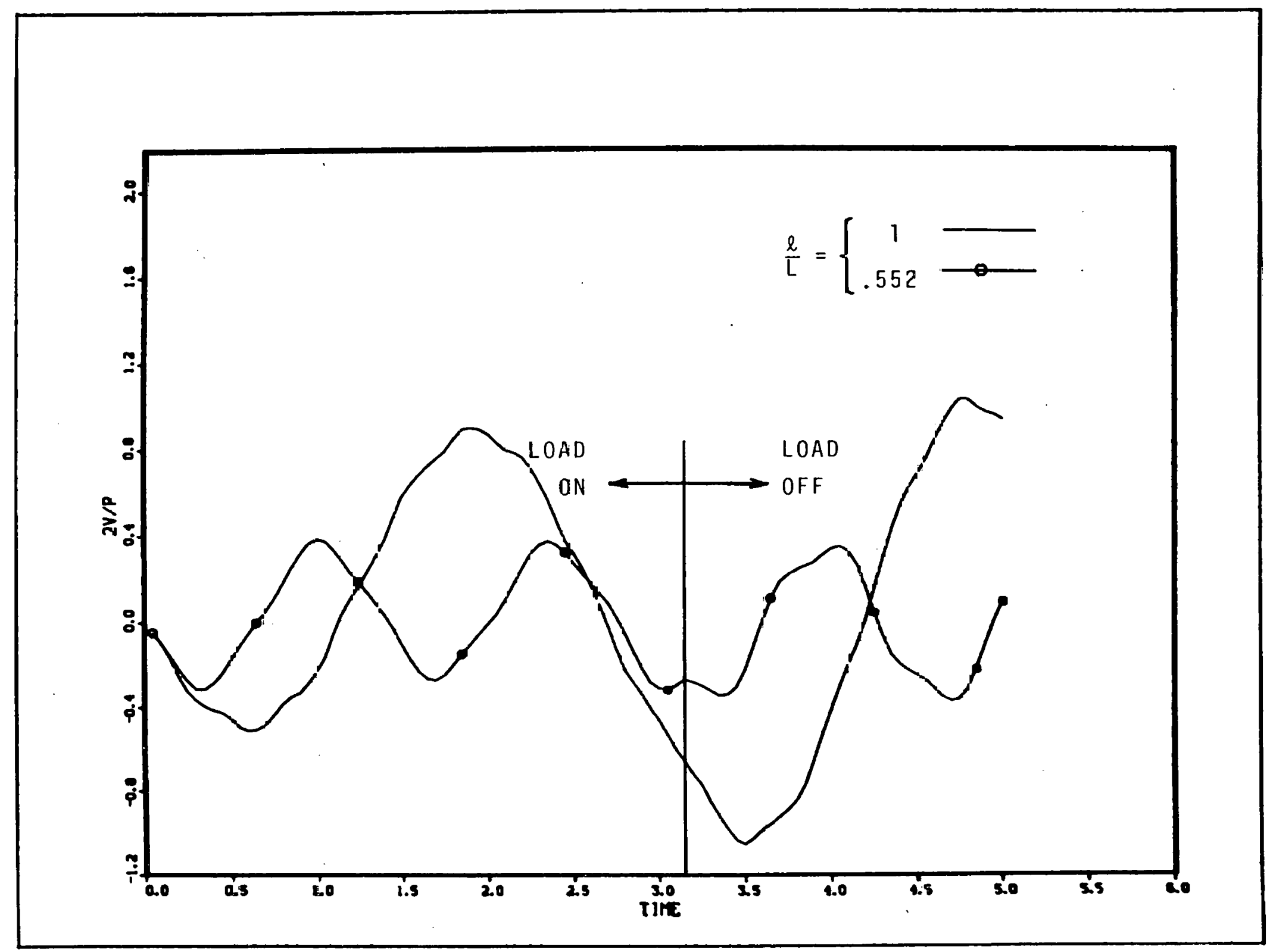

FIGJRE 3. EFROR VS, TIME W:TH AND WITHDUT AN OVERHANG FOR $\mathrm{K}^{3} / \mathrm{EI}=100$ A.ND $\omega=0.1$ 


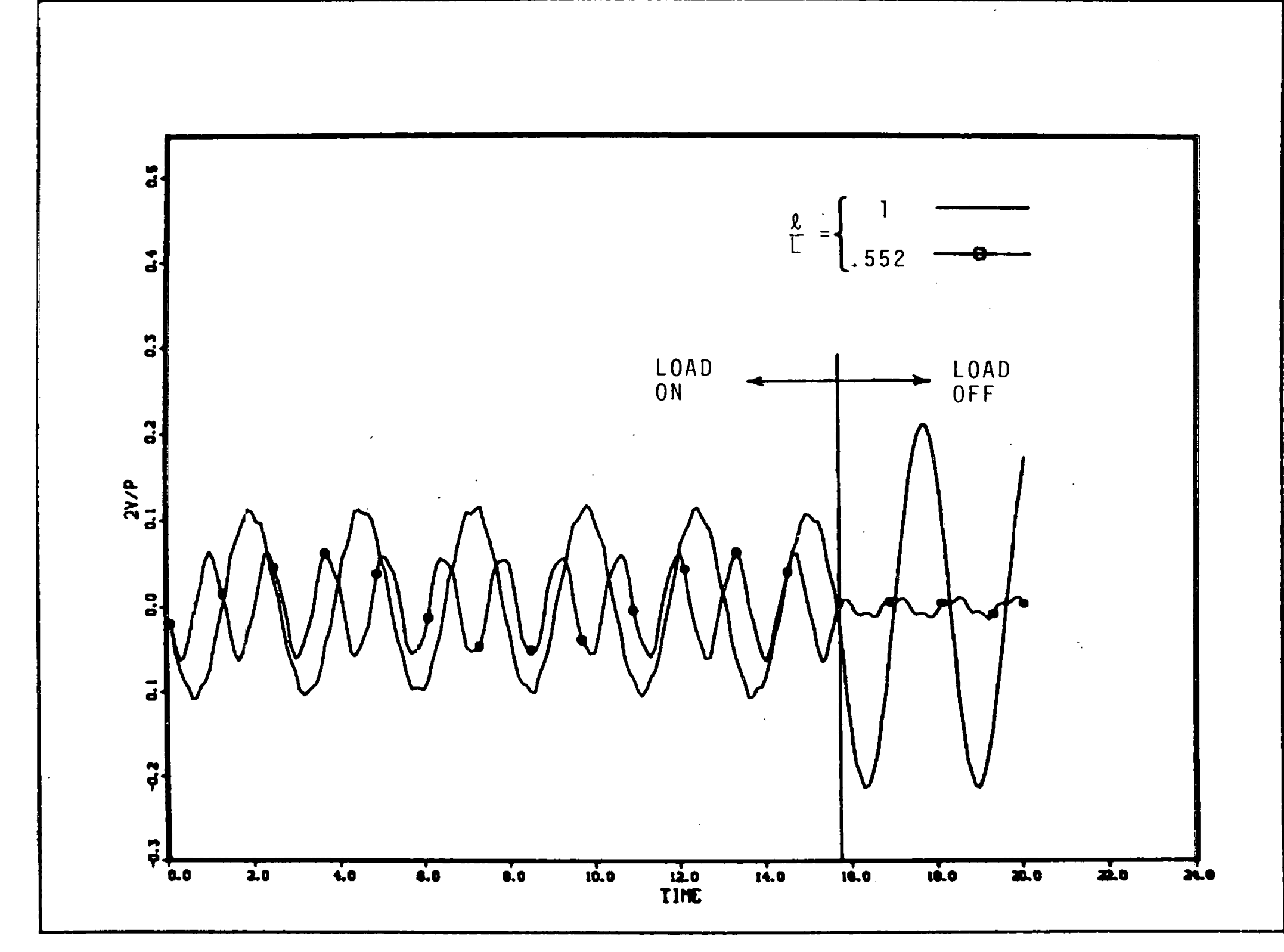


Peak Load Intens"ty

$\underset{D}{N}$

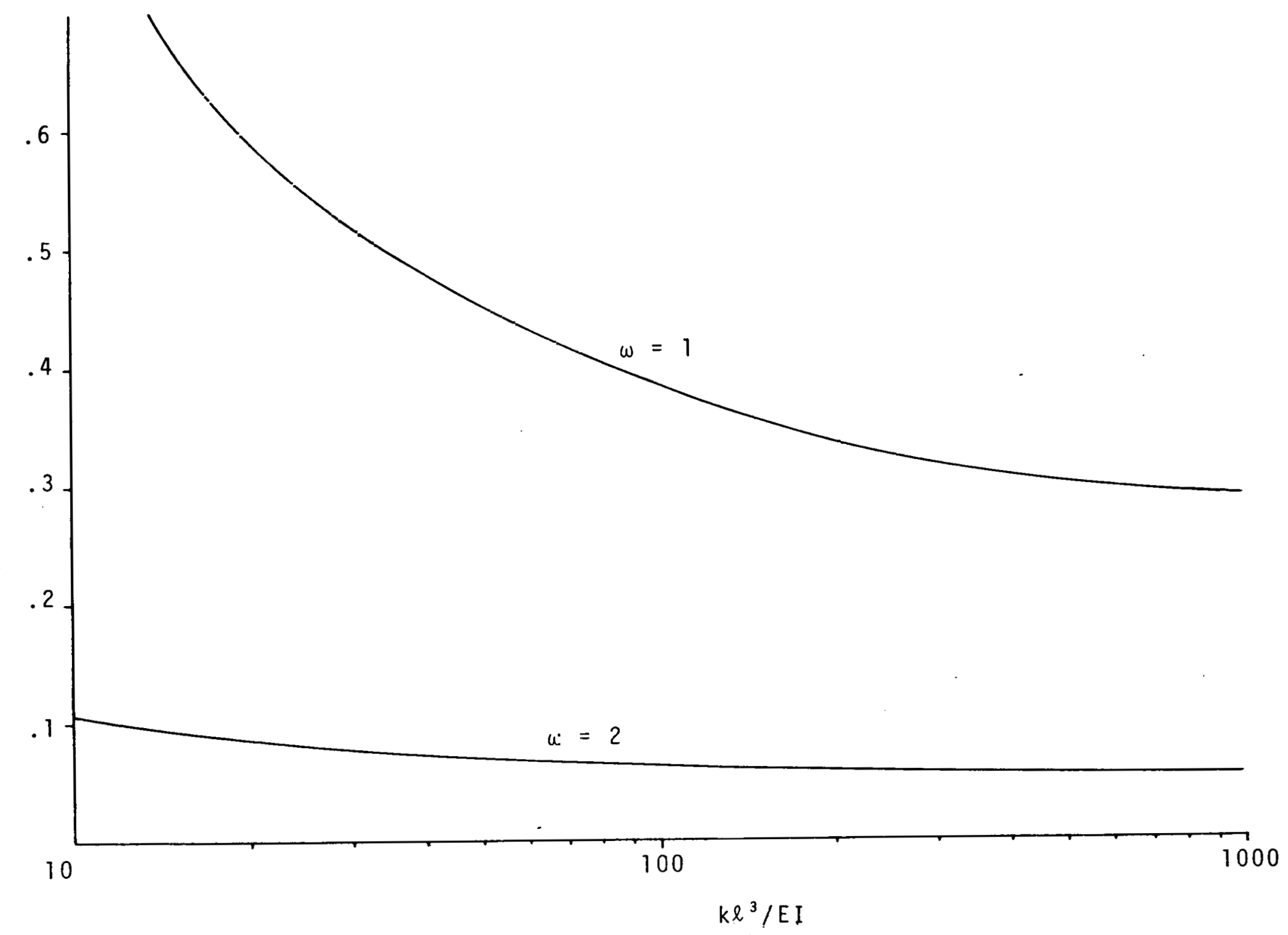

FIGURE 5 , ERROR VS, LOAL CELL STIFFNESS PARAMETER FOR TWO DIFFERENT LOAD DURATIONS AND FOR A TABLE WITH AN OVERHANG. 

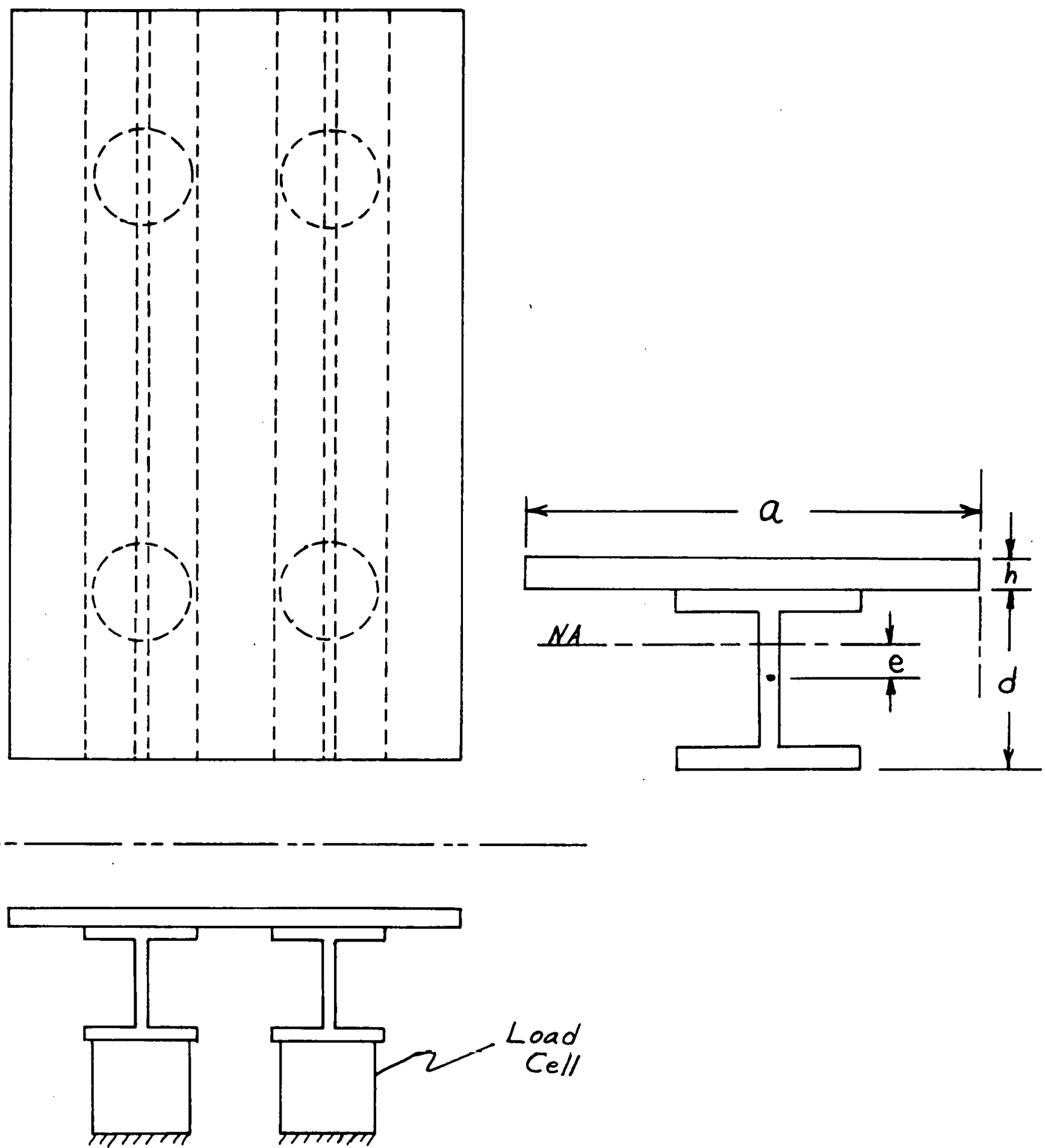

FIGURE 6. DROP TABLE DESIGN USED FOR THE NUMERICAL EXAMPLE. 


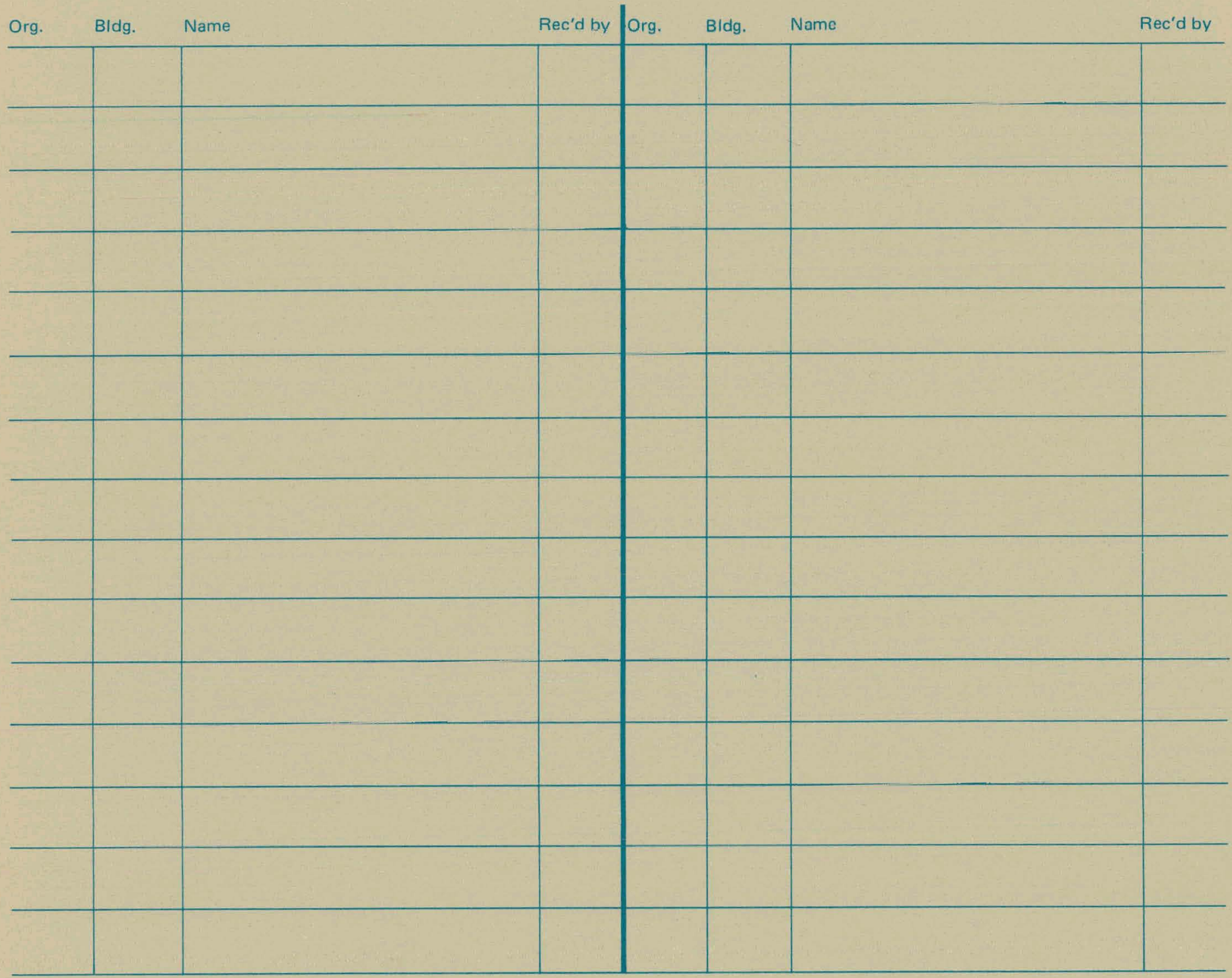

